\title{
玉米种质资源大规模多年多点多病害的自然发病抗性鉴定
}

\author{
段灿星 $^{1}$ 董怀玉 $^{2}$ 李 晓 ${ }^{3}$ 李 红 $^{4}$ 李春辉 $^{1}$ 孙素丽 $^{1}$ 朱振东 $^{1}$ \\ 王晓鸣 1 ,*
}

${ }^{1}$ 中国农业科学院作物科学研究所 / 农作物基因资源与基因改良国家重大科学工程, 北京 $100081 ;{ }^{2}$ 辽宁省农业科学院植物保护研究 所, 辽宁沈阳 $110161 ;{ }^{3}$ 四川省农业科学院植物保护研究所, 四川成都 $610066 ;{ }^{4}$ 吉林省农业科学院植物保护研究所, 吉林公主岭 136100

摘 要: 病害是影响玉米生产的重要因素。利用品种的抗性是控制玉米病害的经济、安全和有效措施。2016一2019 年间, 在黄淮海和东华北地区, 首次对 2000 份来源广泛且遗传背景丰富的玉米种质资源进行了多年多点多病害的田 间自然发生条件下抗病性鉴定, 部分材料在西北地区也进行了田间鉴定, 重点调查了小玟病、茎腐病、瘤黑粉病、弯 孢叶斑病、南方锈病、粗缩病、大斑病、灰斑病和丝黑穗病的抗病性。综合 4 年共 10 个不同环境的自然发病下抗性 鉴定数据表明, 自然发病鉴定的结果受环境因素影响较大, 表现为年度间和地域间的差异。在所有鉴定的病害中, 小 斑病在多个年份和多个鉴定点的发病均比较充分, 11 份种质对该病害表现出稳定抗性; 茎腐病、大斑病和灰斑病, 在 不同年份的部分鉴定点发病较为充分, 对这 3 种病害表现抗病的种质分别为 440、356 和 423 份, 综合抗性鉴定结果 具有较大的参考价值; 弯孢叶斑病、瘤黑粉病和粗缩病仅在 1 个鉴定点发病较为充分, 南方锈病和丝黑穗病在所有鉴 定点均发生较轻, 鉴定结果有待进一步验证。本研究篮选出一批在不同环境条件下对多种病害均具有稳定抗性的材 料，其中 JN15、953、沈 977、68122、K21、SC24-1、17MC7211、17MC7223、郑 591、161191 等种质的综合抗性 突出, 对种质的利用及后续人工接种精准鉴定的种质选择具重要参考价值。

关键词: 玉米种质; 病害; 多年多点; 自然发病鉴定

\section{A large-scale screening of maize germplasm for resistance to multiple diseases in multi-plot demonstration for several years under natural condition}

\author{
DUAN Can-Xing ${ }^{1}$, DONG Huai-Yu ${ }^{2}$, LI Xiao ${ }^{3}$, LI Hong ${ }^{4}$, LI Chun-Hui ${ }^{1}$, SUN Su-Li ${ }^{1}$, ZHU Zhen-Dong $^{1}$, and \\ WANG Xiao-Ming,

\begin{abstract}
${ }^{1}$ Institute of Crop Sciences, Chinese Academy of Agricultural Sciences / National Key Facility for Crop Gene Resources and Genetic Improvement, Beijing 100081, China; ${ }^{2}$ Institute of Plant Protection, Liaoning Academy of Agricultural Sciences, Shenyang 110161, Liaoning, China; ${ }^{3}$ Institute of Plant Protection, Sichuan Academy of Agricultural Sciences, Chengdu 610066, Sichuan, China; ${ }^{4}$ Institute of Plant Protection, Jilin Academy of Agricultural Sciences, Gongzhuling 136100, Jilin, China
\end{abstract}

\begin{abstract}
Disease is a major factor affecting maize production. The utilization of resistant cultivars is the most economical, safe, and effective method for controlling maize diseases. This research was finally conducted using 2000 maize germplasm accessions with extensive sources and rich genetic background to identify and evaluate the resistance to multiple diseases in multi-plot demonstration for several years under natural condition during 2016-2019. Nine diseases, including southern corn leaf blight, stalk rot, common smut, Curvularia leaf spot, southern rust, maize rough dwarf, northern corn leaf blight, gray leaf spot and head smut were investigated and evaluated in non-inoculated fields. The experimental data at 10 different sites from 2016 to 2019 showed that resistance identification under natural conditions was sensitive to environmental factors, with distinct differences among years and regions. The incidence of southern corn leaf blight was severe at multiple sites over these years and 11 maize accessions with
\end{abstract}

\section{本研究由国家重点研发计划项目(2016YFD0100103)和作物种质资源保护专项(2019NWB036-12)资助。}

This study was supported by the National Key Research and Development Program of China (2016YFD0100103) and the Special Fund for Protection of Crop Germplasm Resources (2019NWB036-12).

* 通信作者(Corresponding author): 王晓鸣, E-mail: wangxiaoming@caas.cn

第一作者联系方式: E-mail: duancanxing@caas.cn

Received (收稿日期): 2020-01-17; Accepted (接受日期): 2020-03-24; Published online (网络出版日期): 2020-04-07.

URL: http://kns.cnki.net/kcms/detail/11.1809.S.20200407.1321.002.html 
stable resistance were screened out. Stalk rot, northern corn leaf blight, and gray leaf spot were relatively serious at several sites in four years, and 440, 356, and 423 resistant germplasm were screened out from 2000 accessions, respectively. These integrated data had considerable reference values. Curvularia leaf spot, common smut, and maize rough dwarf occurred heavily at only one plot while southern rust and head smut were not serious at all experimental sites, which should be studied further more. All in all, some maize germplasm resources with stable resistance to diverse diseases under different environments were screened out, such as JN15, 953, Shen 977, 68122, K21, SC24-1, 17MC7211, 17MC7223, Zheng 591, 161191, and so on. These results provide a significant reference for utilization and selection of germplasm for further precise inoculated identification.

Keywords: maize germplasm; disease; multi-plot demonstration for several years; non-inoculated resistance identification

玉米(Zea mays L.) 是我国主要的粮食和饲料作 物, 也是重要的工业原料和能源植物, 在国民经济 和农业生产中占有重要地位, 2012 年玉米播种面积 为 3503 万公顷, 总产量 20,561.4 万吨, 分别为谷物 总种植面积和总产量的 $37.82 \%$ 和 $38.12 \%$, 超越水稻 成为我国第一大粮食作物 (http://www.stats.gov.cn/ tjsj/2013/indexch.htm)；2015 年玉米播种面积和总产 均创历史新高, 分别达到 3811.9 万公顷和 $22,463.2$ 万 吨 (http://www.stats.gov.cn/tjsj/ndsj/2016/indexch. $\mathrm{htm})$ 。因此, 玉米生产的稳定性和安全性直接影响到 我国粮食作物的生产安全和延伸产业的健康发展。 近年来, 随着农业种植业结构调整和耕作栽培方式 转变、玉米品种更替以及全球性气候变暖, 玉米病 虫害发生呈持续加重趋势, 已成为制约玉米高产稳 产的重要因素 ${ }^{[1-3]}$ 。据估测和统计, 全球因病虫害造 成的玉米产量损失达 $19.5 \%$ 41.1\%, 而随着未来环 境温度的上升, 病虫害对玉米造成的损失将进一步 加剧 ${ }^{[1,3]}$ 。我国玉米主要病虫害带来的产量损失总量 自 2010 开始已持续超过了水稻病虫害引发的水稻 产量损失总量 ${ }^{[4]}$ 。因此, 控制玉米病虫害, 对于保障 玉米的安全生产, 具有十分重要的意义。

目前, 我国生产上常见的重要病害主要包括小 斑病、大斑病、茎腐病(腐霉茎腐病、镰狍茎腐病)、 穗腐病(拟轮枝镰孢穗腐病、禾谷镰孢穗腐病)、粗缩 病、纹枯病、瘤黑粉病、丝黑穗病、南方锈病、灰 斑病和弯孢叶斑病等, 其中黄淮海地区以小斑病、 茎腐病、穗腐病、瘤黑粉病、南方锈病、弯孢叶斑 病和粗缩病为主, 东北地区以大斑病、茎腐病、穗 腐病、灰斑病和丝黑穗病为主, 上述病害常年或间 歇性大发生, 给我国玉米生产造成了重大的损失。

其中小斑病感病品种在一般发病年份减产 $10 \%$ 以上, 严重发生年份减产 $20 \% \sim 30 \%{ }^{[5]}$ 。1 1970 年, 由于小斑 病菌 $\mathrm{T}$ 小种的流行, 美国许多田块产量损失 $80 \%$ 以 上, 甚至引起绝产, 损失达 165 亿千克, 价值 10 亿 美元 $^{[6]}$ 。大斑病在流行年份, 感病品种的损失可达 $30 \%$, 甚至高达 50\%以上, 黑龙江省每年因大斑病
而造成产量损失 6 万 9 万吨。我国曾在 20 世纪 70 年代初期、90 年代初期、2003-2006 年以及 2012-2013 年发生大斑病的流行 ${ }^{[7-9]}$ 。在东北和西南 地区，玉米灰斑病爆发时产量损失 $10 \%$ 60\%, 局部 地区减产 $80 \%{ }^{[9-12]}$ 。20 世纪 90 年代, 弯狍叶斑病在 河北省发生面积达 1.3 万公顷以上, 减产 $20 \%$ ～ $00 \%$, 1996 年, 该病在辽宁省暴发面积高达 16.8 万公顷, 损失玉米约 2.5 亿千克 ${ }^{[5,13]}$ 。南方锈病一般造成玉米 减产 $20 \% \sim 30 \%$, 重者可达 $80 \%$ 以上, 甚至绝收 ${ }^{[14-15]}$ 。 茎腐病田间发病率通常为 $5 \%$ 10\%, 在病害重发年 份, 田间发病率为 $20 \% \sim 30 \%$, 一些感病品种的发病 率为 40\% $80 \%$, 可以引起 30\%以上的产量损失 ${ }^{[16-17]}$ 。 玉米穗腐病的发病率通常为 $5 \%$ 10\%, 重发年份为 $30 \% \sim 40 \%$, 感病品种可高达 $50 \%$ 以上, 产量损失更 高达 $30 \% \sim 40 \%{ }^{[18-19]}$ 。除籽粒腐烂造成产量损失外, 其致病镰狍菌能够产生多种毒素, 如伏马毒素、呕 吐毒素和赤霉烯酮等, 降低玉米品质, 给食品与饲料 安全带来重大隐患, 直接威胁到人畜健康 ${ }^{[20-24]}$ 。

众多研究和实践证明，利用抗病品种是控制玉 米病害的经济、安全而有效的措施 ${ }^{[5,19,25-28]}$ 。优异的 抗性种质是抗病品种选育的前提和基础。为此, 国 内外开展了一系列玉米大斑病、小斑病、灰斑病、 南方锈病、粗缩病、纹枯病、茎腐病和穗腐病等重 要病害的抗性鉴定与评价工作, 篮选出一批抗性种 质, 在此基础上, 培育出一些抗病品种或创新种质, 并用于生产实践，对抑制相关病害的流行和发展起 到了十分重要的作用 ${ }^{[15,17,19,25-35]}$ 。然而, 我国幅员辽 阔, 生态坏境复杂多变, 导致病害种类繁多, 致病 菌变异分化较大, 因此, 现有的抗病品种根本不足 以满足生产的需求, 各生态区病害仍然频发, 抗病 品种选育和应用任重道远。我国玉米种质资源的保 藏量十分丰富, 但大部分种质资源都未进行充分的 抗病鉴定和用于抗病育种, 且以往的抗病鉴定工作 大多在固定的鉴定圑完成，很少开展多年多点的鉴 定，因此，不能明确所鉴定种质在不同年份和不同 环境下的抗性表现。 
本研究在 2016-2019 年间，开展了玉米种质资 源大规模多年多点的田间自然发病鉴定, 对 2000 余 份来源广泛、具有丰富遗传多样性的玉米种质资源 进行了抗小斑病、茎腐病、大斑病、灰斑病、南方 锈病、瘤黑粉病、弯孢叶斑病和粗缩病的自然发病 鉴定, 以期明确这些种质在大田正常生长条件和环 境下, 在不同年份以及不同地点, 对某种病害的抗 性水平以及对不同类型病害的综合抗性; 在此基础 上，结合这些种质的农艺性状表型，篮选出 400 500 份综合性状较为突出的代表性种质, 用于多年多点 的人工接种抗病鉴定，以获得精确的抗病鉴定表型 数据, 篮选出不同年份和不同环境下均有稳定抗性 表现的玉米种质, 为抗病育种提供了可利用的抗性 资源。

\section{1 材料与方法}

\section{1 供试植物材料}

由国家重点研发计划“玉米种质资源精准鉴定 与创新利用”项目组提供的 2000 份来源广泛且具有 丰富遗传多样性的玉米自交系。

\section{2 田间试验设计及管理}

田间自然发病鉴定地点均设置在玉米主产区, 包括河南原阳 $\left(35^{\circ} 05^{\prime} \mathrm{N}, 113^{\circ} 97^{\prime} \mathrm{E}\right)$ 、山东章丘 $\left(36^{\circ} 43^{\prime} \mathrm{N}, 117^{\circ} 30^{\prime} \mathrm{E}\right)$ 、北京顺义 $\left(40^{\circ} 13^{\prime} \mathrm{N}, 116^{\circ} 34^{\prime} \mathrm{E}\right)$ 、 北京房山 $\left(39^{\circ} 38^{\prime} \mathrm{N}, 116^{\circ} 04^{\prime} \mathrm{E}\right)$ 、辽宁沈阳 $\left(42^{\circ} 04^{\prime} \mathrm{N}\right.$, $\left.123^{\circ} 58^{\prime} \mathrm{E}\right) 、$ 吉林公主岭 $\left(43^{\circ} 30^{\prime} \mathrm{N}, 124^{\circ} 48^{\prime} \mathrm{E}\right)$ 、黑龙江 哈尔滨 $\left(45^{\circ} 75^{\prime} \mathrm{N}, 126^{\circ} 63^{\prime} \mathrm{E}\right)$ 、山西定襄 $\left(38^{\circ} 33^{\prime} \mathrm{N}\right.$, $\left.112^{\circ} 54^{\prime} \mathrm{E}\right)$ 、甘肃张掖 $\left(38^{\circ} 83^{\prime} \mathrm{N}, 100^{\circ} 36^{\prime} \mathrm{E}\right)$ 和陕西咸阳 $\left(34^{\circ} 03^{\prime} \mathrm{N}, 108^{\circ} 09^{\prime} \mathrm{E}\right)$ 。

采取随机排列, $3 \mathrm{~m}$ 行长, 单行种植, 2 3 次重 复。定苗时控制植株密度为 60,000 67,500 株 $\mathrm{hm}^{-2}$ 。 采用双小区(背靠背)种植(中间种植高粱或留 $40 \mathrm{~cm}$ 的小过道), $80 \mathrm{~cm}$ 宽的观察道。

选择具有代表性, 中上等肥力水平试验地。试 验田平整、平坦, 施肥水平及其他管理与当地生产 水平相当。在土壤湿度适宜时播种, 力保全苗。播 种后, 及时施用一次苗前除草剂。生长季内, 不喷施 杀菌剂。

\section{3 田间病害自然发生状况}

在玉米生长后期(乳熟末期至蜡熟期), 对各生 态区的自然发病鉴定固和代表性的周边生产大田进 行病害普查, 重点调查主要病害的发生程度, 记录 病害级别或发病率，明确该年份不同生态区田间玉
米病害自然发生的状况。

\section{4 病害鉴定与评价}

1.4 .1 叶部真菌病害 主要鉴定 2000 份玉米种 质对小斑病、弯孢叶斑病、南方锈病、大斑病和灰 斑病的田间抗病性。所有鉴定玉米材料生长期内自 然发病, 在蜡熟期采用目测法调查发病情况, 参照 “玉米抗病虫性鉴定技术规范”的病情调查和评价标 准, 记载每个品种的病级, 进行抗性评价。

参照“玉米抗病虫性鉴定技术规范 第 2 部分: 玉米抗小斑病鉴定技术规范(NY/T 1248.2-2006)”进 行小斑病自然发病鉴定 ${ }^{[36]}$, 重点调查“棒三叶”(穗 位叶、穗下第 1 叶和穗上第 1 叶)的发病状况。参照 “玉米抗病虫性鉴定技术规范 第 10 部分: 弯狍叶斑 病(NY/T 1248.10-2016)”鉴定弯孢叶斑病抗性 ${ }^{[37]}$, 重 点调查玉米穗位叶及其上方 3 个叶片的发病程度。 参照陈文娟等 ${ }^{[15,38]}$ 的方法鉴定南方锈病抗性, 重点 调查“棒三叶”(穗位叶、穗下第 1 叶和穗上第 1 叶) 的发病情况。参照“玉米抗病虫性鉴定技术规范 第 1 部分：玉米抗大斑病鉴定技术规范 (NY/T

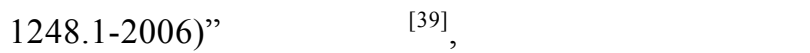
及其上方 3 个叶片的病级。参照“玉米抗病虫性鉴定 技术规范 第 11 部分: 灰斑病(NY/T 1248.11-2016)” 鉴定灰斑病 ${ }^{[40]}$, 重点调查玉米穗位叶及其上方 3 个 叶片的发病情况。

\subsection{2 茎部真菌病害参照“玉米抗病虫性鉴定} 技术规范 第 6 部分：腐霉茎腐病 $(\mathrm{NY} / \mathrm{T}$ 1248.6-2016)”和“玉米抗病虫性鉴定技术规范 第 7 部分：镰孢茎腐病(NY/T 1248.7-2016)”鉴定自然发 病条件下玉米种质对茎腐病的抗性 ${ }^{[41-42]}$ 。生长期间 自然发病, 蜡熟后期采用目测典型症状如植株明显 枯黄/枯死/果穗倒挂等, 结合手捏法调查。茎基部变 软、空松, 能用手捏动植株判定为发病株。调查发 病株数、总株数, 计算发病率, 进行抗性评价。

\subsection{3 穗部真菌病害分别参照“玉米抗病虫性} 鉴定技术规范第 12 部分：瘤黑粉病 (NY/T 1248.12-2016)”和“玉米抗病虫性鉴定技术规范 第 3 部分：玉米抗丝黑穗病鉴定技术规范 (NY/T 1248.3-2006)”鉴定 2000 份玉米种质对瘤黑粉病和丝 黑穗病的抗性 ${ }^{[43-44]}$ 。生长期间自然发病, 乳熟期进 行病害调查, 调查发病株数、总株数, 计算发病率。

\subsection{4 病毒病参照“玉米抗病虫性鉴定技术规} 范 第 13 部分: 粗缩病(NY/T 1248.13-2016)”鉴定 玉米种质在自然发病条件下对粗缩病的抗性 ${ }^{[45]}$ 。生 
长期间自然感病, 在大喇叭口期至灌浆期调查发病 情况, 植株出现典型粗缩病症状即为发病株。调查 发病株数、总株数, 计算发病率。

\section{2 结果与分析}

\section{1 田间玉米病害自然发生状况}

2016-2019年间，对各自然发病鉴定固和周边 大田生产上的玉米病害发生状况调查表明，在田间 自然发病的条件下，玉米病害的发生程度在年度间 和地域间表现出较大的差异。2016年, 黄淮海地区 玉米自交系上的小斑病发生较重, 其他病害自然发 生较轻。2017年, 黄淮海地区自交系的小斑病严重 发生, 茎腐病、瘤黑粉病和穗腐病偏重发生; 东华北 地区茎腐病和灰斑病发生较重, 其余病害发生偏轻; 西北部分地区茎腐病偏重发生。2018年, 黄淮海地 区小玟病总体发生较重, 弯孢叶斑病在部分区域偏 重发生, 穗腐病普遍发生, 茎腐病偏重发生; 东华 北部分区域茎腐病发生较重, 其余病害发生较轻; 西北试验点大斑病和茎腐病发生较重。2019年, 黄 淮海地区小斑病和弯狍叶斑病中等偏重发生, 粗缩 病发生较重, 其余病害发生轻微; 东华北地区大斑
病和灰斑病发生较重, 部分地区茎腐病发生较重, 其余病害偏轻发生; 西北地区部分区域茎腐病和大 斑病发生偏重, 其余病害轻微发生。

\section{2 玉米种质对重要病害的自然发病鉴定与评价}

2.2.1 小斑病鉴定 小玟病是夏玉米区生产上 的重要病害, 重点调查河南原阳、山东章丘、北京 顺义和房山鉴定圑的发病情况表明，2016-2019 年间, 小玟病自然发病整体较重, 在 2000 份自交 系中, 表现感病和高感的种质占总鉴定材料的 $50 \%$ 以上，但在不同年份间和不同环境下，发病 程度差异较大, 2016-2017年, 各鉴定点小斑病均 发生严重, 2018-2019 年相对较轻, 其中 2017 年 山东章丘发生最为严重, 2000 份材料中对小斑病 表现高感和感病的种质分别占 $47.9 \%$ 和 $44.7 \%$, 其 次是 2017 年河南原阳, 高感和感病材料分别占 $36.7 \%$ 和 36.5\%; 此外, 2016 年北京房山和 2018 年 北京顺义，小玟病自然发病均比较充分。通过对 4 年各个鉴定点的抗性鉴定分析, H599a、MC7470、 W-25、绵 983 等 11 份种质对小斑病的综合抗性表 现稳定, 在各年各点对小斑病的抗性均表现为中 抗至高抗水平(表 1 )。

表 $12016-2019$ 年间 11 份种质在各鉴定点的小斑病病情级别与综合抗性水平

Table 1 Disease scales and resistance of southern corn leaf blight among 11 maize germplasm at different sites during $2016-2019$

\begin{tabular}{|c|c|c|c|c|c|c|c|c|c|c|c|c|c|c|}
\hline \multirow{2}{*}{$\begin{array}{c}\text { 种质名称 } \\
\text { Name }\end{array}$} & \multicolumn{3}{|c|}{2016} & \multicolumn{3}{|c|}{2017} & \multicolumn{3}{|c|}{2018} & \multicolumn{3}{|c|}{2019} & \multirow{2}{*}{$\begin{array}{l}\text { 最高 } \\
\text { 病级 } \\
\text { Scale }\end{array}$} & \multirow{2}{*}{$\begin{array}{l}\text { 综合抗性 } \\
\text { Resistance }\end{array}$} \\
\hline & $\begin{array}{c}\text { 北京 } \\
\text { BJ }\end{array}$ & $\begin{array}{c}\text { 河南 } \\
\mathrm{HN} \\
\end{array}$ & $\begin{array}{c}\text { 山东 } \\
\text { SD } \\
\end{array}$ & $\begin{array}{c}\text { 北京 } \\
\text { BJ }\end{array}$ & $\begin{array}{c}\text { 河南 } \\
\mathrm{HN} \\
\end{array}$ & $\begin{array}{c}\text { 山东 } \\
\text { SD }\end{array}$ & $\begin{array}{c}\text { 北京 } \\
\text { BJ }\end{array}$ & $\begin{array}{c}\text { 河南 } \\
\mathrm{HN} \\
\end{array}$ & $\begin{array}{c}\text { 山东 } \\
\text { SD } \\
\end{array}$ & $\begin{array}{c}\text { 北京 } \\
\text { BJ }\end{array}$ & $\begin{array}{c}\text { 河南 } \\
\mathrm{HN} \\
\end{array}$ & $\begin{array}{c}\text { 山东 } \\
\text { SD }\end{array}$ & & \\
\hline H599a & 5 & 5 & 5 & 5 & 3 & 5 & 3 & 3 & 5 & 3 & 3 & 3 & 5 & MR \\
\hline HRB16198 & 5 & 3 & 3 & 3 & 3 & 5 & 3 & 5 & 3 & 3 & 3 & 3 & 5 & MR \\
\hline MC7470 & 5 & 3 & 3 & 5 & 5 & 3 & 3 & 3 & 3 & 5 & 3 & 1 & 5 & MR \\
\hline MC7480 & 5 & 5 & 5 & 5 & 5 & 5 & 5 & 5 & 5 & 3 & 3 & 3 & 5 & MR \\
\hline MC7487 & 3 & 3 & 5 & 5 & 3 & 5 & 3 & 3 & 3 & 1 & 3 & 3 & 5 & MR \\
\hline MC7527 & 3 & 3 & 5 & 5 & 5 & 5 & 3 & 5 & 3 & 1 & 3 & 3 & 5 & MR \\
\hline MC7542 & 5 & 3 & 3 & 5 & 3 & 5 & 3 & 5 & 3 & 1 & 3 & 3 & 5 & MR \\
\hline MC7549 & 3 & 3 & 5 & 5 & 5 & 5 & 5 & 3 & 5 & 3 & 3 & 3 & 5 & MR \\
\hline W-25 & 3 & 3 & 5 & 5 & 3 & 5 & 3 & 3 & 3 & 1 & 3 & 3 & 5 & MR \\
\hline X324 & 5 & 3 & 3 & 5 & 3 & 5 & 3 & 5 & 3 & 1 & 3 & 3 & 5 & MR \\
\hline 绵 983 Mian 983 & 5 & 3 & 3 & 3 & 5 & 5 & 5 & 3 & 3 & 3 & 3 & 3 & 5 & MR \\
\hline
\end{tabular}

BJ: Beijing; HN: Henan; SD: Shandong; MR: moderately resistant.

\subsection{2 弯狍叶斑病鉴定弯狍叶斑病是夏玉米区} 常见的叶斑病，2016-2019 年间，主要调查了河南 原阳、山东章丘、北京顺义和北京房山鉴定点的发 病情况，表明各年份和各鉴定点的弯孢叶斑病发生 整体较轻, 仅 2019 年北京顺义发生较重, 2000 份自 交系中, 对弯狍叶斑病表现感病和高感的种质占比
分别为 $20.5 \%$ 和 $0.6 \%$ 。由于这 4 年其他各鉴定点的 材料发病程度轻微，因此该病害自然发病鉴定的结 果仅供参考。

2.2.3 南方锈病鉴定南方锈病是我国夏玉米区 和热带亚热带玉米区的重要病害, 受热带气旋的活 动路径影响较大。2016-2019 年期间, 黄淮海夏玉 
米区没有发生南方锈病大范围流行事件，只在局部 地区的一些材料被害严重。河南原阳、山东章丘、 北京顺义和北京房山 4 个鉴定点在 4 年间的发病程 度轻微, 感病和高感南方锈病的种质占比分别为 $16.3 \%$ 和 $2.7 \%$ ，玉米种质 HRB16169、HRB16198、 M15208、C8605-2、ZK02-1、吉资 1134、陇 1471、 陇 1247、陇 1472、M15208、自 330、辽 3162、PHG39 等高感南方锈病。由于 2016-2019 年间各个鉴定圃 的自然发病均不充分, 因此, 除了感病材料的数据 能真实体现该种质的抗性水平外, 抗病种质的数据 仅供参考。

\subsection{4 大斑病鉴定 大斑病是我国春玉米区的重} 要病害。2016-2019 年期间, 重点调查了辽宁沈阳、 吉林公主岭、黑龙江哈尔滨、山西定襄和陕西咸阳 5 个鉴定点的大斑病发生情况。结果表明, 20162018 年, 2000 份自交系在辽宁沈阳、吉林公主岭和 黑龙江哈尔滨的自然发病均较轻; 2017-2018 年, 山西定襄的大斑病均发生较重, 2019 年, 在辽宁沈 阳和黑龙江哈尔滨发生较重, 在 2 个鉴定点对大斑 病表现感病和高感种质占比分别为 $18.8 \%$ 和 $3.5 \%$ 以 及 $16.6 \%$ 和 $3.7 \%$ 。综合 4 年各个点的自然发病鉴定 数据, 对大斑病表现高抗、抗病和中抗的种质分别 为 17 、339 和 468 份, 9109、丹 598、5N545、LY2211、 JLXH-16、辽 68、丹 598 红轴、LH82、桦 94、CML61、 综 3、京 388 改、郑 586、郑 1358、蒙 17j14、蒙 17j44、 豫 25 共 17 份玉米种质在 4 年多点的自然发病鉴定 中, 均对大斑病表现高抗。

2.2.5 灰斑病鉴定灰斑病也是我国春玉米区的 重要病害。2016-2019 年间, 重点调查辽宁沈阳、 吉林公主岭和黑龙江哈尔滨 3 个鉴定点表明, 灰斑
病自然发病程度整体较轻，但不同年度和不同地点 的发病程度差异较大。其中, 2019 年黑龙江哈尔滨 和 2017 年辽宁沈阳鉴定固的自然发病相对较重, 2000 份自交系中, 对灰斑病表现感病和高感的种质 占比分别为 $18.6 \%$ 和 $2.9 \%$ 以及 $10.5 \%$ 和 $1.8 \%$ 。综合 4 年各个点的自然发病鉴定数据, 对灰斑病表现高 抗、抗病和中抗的种质分别为 17、406 和 539 份, MC4178、MC7468、MC7546、郑 1113V、冀资 S187、 M09N041、16SD003、LD61、PHW06、桦 94、K21、 CML61、赤 545、蒙 17j14、蒙 17j29、蒙 17j44、豫 25 共 17 份种质在 4 年多点的自然发病鉴定中, 均对 灰斑病表现高抗。

2.2.6 茎腐病鉴定茎腐病是我国玉米所有生 态区的重要病害, 对河南原阳、山东章丘、北京顺 义、北京房山、辽宁沈阳、吉林公主岭、黑龙江哈 尔滨、山西定襄、甘肃张掖、山西咸阳的鉴定圃材 料调查鉴定表明，茎腐病田间自然发病受环境影响 大，不同年份间和不同生态环境条件下，发病程度 差异明显。其中, 2017 年辽宁沈阳茎腐病自然发生 较重, 2000 份自交系中, 对茎腐病表现感病和高感 的种质占比分别为 $22.6 \%$ 和 $14.2 \%$; 其次是 2017 年 的北京顺义, 感病和高感茎腐病的种质分别占比 $13.5 \%$ 和 $10.9 \%$; 在山西定襄, 2017-2018 年的茎腐 病均发生较重, 2017 年对茎腐病表现感病和高感的 种质分别占总鉴定材料的 $20.7 \%$ 和 $24.5 \%$ 。通过对 2016-2019 年间每年各个鉴定点的抗性鉴定数据 综合分析，发现共有 440 份种质在田间自然发病鉴 定中对茎腐病表现出稳定的抗性, 这些材料将成为 玉米抗茎腐病人工接种精准鉴定种质的重要来源 (表 2)。

表 2 2016-2019 年田间自然发病鉴定中对茎腐病表现高抗的部分种质

Table 2 Some maize germplasm with high resistance to stalk rot screened from naturally infected identification during 2016-2019

\begin{tabular}{|c|c|c|c|c|c|c|c|}
\hline $\begin{array}{l}\text { 名称 } \\
\text { Name }\end{array}$ & $\begin{array}{c}\text { 发病率 } \\
\text { Incidence (\%) }\end{array}$ & $\begin{array}{l}\text { 名称 } \\
\text { Name }\end{array}$ & \begin{tabular}{c||} 
发病率 \\
Incidence (\%)
\end{tabular} & $\begin{array}{l}\text { 名称 } \\
\text { Name }\end{array}$ & $\begin{array}{c}\text { 发病率 } \\
\text { Incidence (\%) }\end{array}$ & $\begin{array}{l}\text { 名称 } \\
\text { Name }\end{array}$ & $\begin{array}{c}\text { 发病率 } \\
\text { Incidence }(\%)\end{array}$ \\
\hline $16 \mathrm{SD} 001$ & 4.2 & HRB16210 & 0 & Y378 & 4.5 & 辽 20382 Liao 20382 & 4.5 \\
\hline 16SD007 & 4.8 & J005 & 4.8 & 丹 1133 Dan 1133 & 0 & 辽 2309 Liao 2309 & 0 \\
\hline 16SD069 & 0 & M44928 & 4.3 & 丹 599 Dan 599 & 4.2 & 辽 5090 Liao 5090 & 4.5 \\
\hline 16SD082 & 4.3 & M45638 & 4.2 & 吉资 1046 Jizi 1046 & 0 & 辽 785 Liao 785 & 0 \\
\hline 16SD119 & 4.5 & M5168 & 4.8 & 吉资 1137 Jizi 1137 & 4.0 & 辽 8821 Liao 8821 & 4.2 \\
\hline 16SD122 & 0 & MC7452 & 4.5 & 吉资 1138 Jizi 1138 & 4.5 & 陇 0988 Long 0988 & 4.8 \\
\hline 16SD153 & 3.8 & MC7470 & 4.5 & 冀 SX32T29 Ji SX32T29 & 3.8 & 陇 1103 Long 1103 & 0 \\
\hline 16SD176 & 0 & MC7473 & 0 & 冀 SX32T31 Ji SX32T31 & 4.5 & 陇 1307 Long 1307 & 0 \\
\hline 214CTS & 0 & MC7494 & 0 & 冀资 13W142 Jizi 13W142 & 0 & 陇 1401 Long 1401 & 3.6 \\
\hline
\end{tabular}


(续表 2)

\begin{tabular}{|c|c|c|c|c|c|c|c|}
\hline $\begin{array}{l}\text { 名称 } \\
\text { Name }\end{array}$ & \begin{tabular}{c||} 
发病率 \\
Incidence (\%)
\end{tabular} & $\begin{array}{l}\text { 名称 } \\
\text { Name }\end{array}$ & $\begin{array}{c}\text { 发病率 } \\
\text { Incidence }(\%)\end{array}$ & $\begin{array}{l}\text { 名称 } \\
\text { Name }\end{array}$ & $\begin{array}{c}\text { 发病率 } \\
\text { Incidence }(\%)\end{array}$ & $\begin{array}{l}\text { 名称 } \\
\text { Name }\end{array}$ & $\begin{array}{c}\text { 发病率 } \\
\text { Incidence (\%) }\end{array}$ \\
\hline $5 \mathrm{~N} 76$ & 4.2 & MC7504 & 4.2 & 冀资 14W108 Jizi 14W108 & 4.2 & 陇 M0304 Long M0304 & 0 \\
\hline $\mathrm{C} 89$ & 0 & MC7549 & 4.2 & 冀资 14W290 Jizi 14W290 & 3.6 & 沈 3336 Shen 3336 & 3.8 \\
\hline D26 & 4.8 & X102 & 0 & 冀资 H635 Jizi H635 & 0 & H06-71 & 4.2 \\
\hline DN6217 & 0 & X324 & 0 & 冀资 S187 Jizi S187 & 4.5 & 铁 0255-1 Tie 0255-1 & 0 \\
\hline DXA001 & 4.2 & Y1630 & 4.2 & 冀资 S735 Jizi S735 & 4.5 & 铁 20135 Tie 20135 & 4.0 \\
\hline FZ30 & 0 & Y1632 & 0 & $\mathrm{R} 8-96$ & 4.5 & 铁 7922 Tie 7922 & 0 \\
\hline G285 & 0 & Y1680 & 4.5 & $\mathrm{X} 8531$ & 0 & $\mathrm{PH} 2 \mathrm{VK}$ & 4.3 \\
\hline H050 & 0 & Y1685 & 4.5 & $\mathrm{CH} 7-2-1$ & 3.6 & PH6JM & 3.4 \\
\hline HRB16074 & 0 & Y1687 & 4.3 & Ds- $12 \mathrm{a}$ & 3.8 & PHPMO & 0 \\
\hline HRB16101 & 4.5 & Y1711 & 4.8 & X901 & 3.6 & W314 & 3.8 \\
\hline HRB16109 & 0 & Y1720 & 0. & 浚 248 Xun 248 & 3.8 & $\mathrm{X} 48 \mathrm{~B}$ & 4.8 \\
\hline HRB16134 & 3.8 & Y1754 & 4.2 & HRB16209 & 3.8 & 运系 98-3 Yunxi 98-3 & 4.2 \\
\hline HRB16142 & 0 & Y1755 & 4.2 & 辽 0558 Liao 0558 & 0 & 辽 106 Liao 106 & 0 \\
\hline
\end{tabular}

2.2.7 瘤黑粉病鉴定瘤黑粉病也是我国玉米生 产上较为常见的病害, 主要发生在夏玉米区, 东北 春玉米区也时有发生。2016-2019 年间, 对河南原 阳、山东章丘、北京顺义、北京房山、辽宁沈阳、 吉林公主岭和黑龙江哈尔滨的种质调查鉴定表明, 瘤黑粉病田间自然发病整体较轻，但在不同年份间 和不同生态环境条件下, 发病程度差异较大。2017 年河南原阳鉴定國的瘤黑粉病自然发生相对较重,
2000 份自交系中，对瘤黑粉病表现感病和高感的种 质占比分别为 $18.0 \%$ 和 $2.4 \%$ 。通过对 2016-2019 年间各个鉴定点的瘤黑粉病鉴定数据综合分析，共 有 726 份种质在田间自然发病鉴定中对瘤黑粉病表 现出稳定的抗性(表 3)。

2.2.8 丝黑穗病鉴定丝黑穗病是我国东华北和 西北春玉米区的重要病害。2016-2019 年期间, 重 点调查辽宁沈阳、吉林公主岭和黑龙江哈尔滨 3 个

表 $32016-2019$ 年田间自然发病鉴定中对瘤黑粉病表现高抗的部分种质

Table 3 Some maize germplasm with high resistance to common smut screened from naturally infected identification during $2016-2019$

\begin{tabular}{|c|c|c|c|c|c|c|c|}
\hline $\begin{array}{l}\text { 名称 } \\
\text { Name }\end{array}$ & $\begin{array}{c}\text { 发病率 } \\
\text { Incidence }(\%)\end{array}$ & $\begin{array}{l}\text { 名称 } \\
\text { Name }\end{array}$ & $\begin{array}{c}\text { 发病率 } \\
\text { Incidence }(\%)\end{array}$ & $\begin{array}{l}\text { 名称 } \\
\text { Name }\end{array}$ & \begin{tabular}{c||} 
发病率 \\
Incidence $(\%)$
\end{tabular} & $\begin{array}{l}\text { 名称 } \\
\text { Name }\end{array}$ & $\begin{array}{c}\text { 发病率 } \\
\text { Incidence (\%) }\end{array}$ \\
\hline 16SD033 & 0 & JLXH-3 & 0 & $\mathrm{P} 138$ & 0 & 冀资 B2042 Jizi B2042 & 0 \\
\hline 16SD069 & 0 & JMO17D & 0 & PH298 & 0 & 冀资 R16 Jizi R16 & 0 \\
\hline $16 \mathrm{SD} 176$ & 0 & K12 & 0 & PHP60 & 0 & 冀资 S187 Jizi S187 & 0 \\
\hline 16SD179 & 0 & KP105 & 0 & SF8 & 0 & 辽 0567 Liao 0567 & 0 \\
\hline $2015 \mathrm{~S} 1093$ & 0 & L98 & 0 & Т0294 & 0 & 辽 106 Liao 106 & 0 \\
\hline $81-4-2$ & 0 & ly5502 & 0 & $\mathrm{~T} 24139$ & 0 & 辽 20382 Liao 20382 & 0 \\
\hline C89 & 0 & M09N142 & 0 & T33448 & 0 & 辽 2572 Liao 2572 & 0 \\
\hline DN1722 & 0 & M10NJ49 & 0 & T5195 & 0 & 辽 63114 Liao 63114 & 0 \\
\hline DXA105 & 0 & M15131 & 0 & T7309 & 0 & 陇 0986 Long 0986 & 0 \\
\hline DXA119 & 0 & M35276 & 0 & T98131 & 0 & 陇 1107 Long 1107 & 0 \\
\hline DXA168 & 0 & M44928 & 0 & TE350 & 0 & 陇 1447 Long 1447 & 0 \\
\hline DXB030 & 0 & M45482 & 0 & $\mathrm{~W} 240$ & 0 & 陇 M0304 Long M0304 & 0 \\
\hline DXB060 & 0 & M45845 & 0 & W9813 & 0 & 陇 M0801 Long M0801 & 0 \\
\hline DXB171 & 0 & MC3361 & 0 & $\mathrm{X} 47 \mathrm{~B}$ & 0 & 陇 M0818 Long M0818 & 0 \\
\hline DXB198 & 0 & MC5836 & 0 & Y1710 & 0 & 明 2325 Ming 2325 & 0 \\
\hline
\end{tabular}


(续表 3)

\begin{tabular}{|c|c|c|c|c|c|c|c|}
\hline $\begin{array}{l}\text { 名称 } \\
\text { Name }\end{array}$ & $\begin{array}{c}\text { 发病率 } \\
\text { Incidence }(\%)\end{array}$ & $\begin{array}{l}\text { 名称 } \\
\text { Name }\end{array}$ & \begin{tabular}{c||} 
发病率 \\
Incidence $(\%)$
\end{tabular} & $\begin{array}{l}\text { 名称 } \\
\text { Name }\end{array}$ & $\begin{array}{c}\text { 发病率 } \\
\text { Incidence } \\
(\%)\end{array}$ & $\begin{array}{l}\text { 名称 } \\
\text { Name }\end{array}$ & $\begin{array}{c}\text { 发病率 } \\
\text { Incidence }(\%)\end{array}$ \\
\hline F665 & 0 & MC5843 & 0 & Y1740 & 0 & 沈 135 Shen 135 & 0 \\
\hline FZ30 & 0 & MC6172 & 0 & Y1741 & 0 & 沈 3336 Shen 3336 & 0 \\
\hline HRB16003 & 0 & MC6180 & 0 & Y1747 & 0 & 绥系 608 Suixi 608 & 0 \\
\hline HRB16006 & 0 & MC7457 & 0 & YCM & 0 & 铁 0519 Tie 0519 & 0 \\
\hline HRB16187 & 0 & MC7546 & 0 & 合系 15-17 Hexi 15-17 & 0 & 铁 20135 Tie 20135 & 0 \\
\hline HRB16201 & 0 & MC9292 & 0 & 吉资 1040 Jizi 1040 & 0 & 郑 32P75 Zheng 32P75 & 0 \\
\hline JLXH-11 & 0 & MC9295 & 0 & 吉资 1140 Jizi 1140 & 0 & 中 451 Zhong 451 & 0 \\
\hline
\end{tabular}

鉴定点的情况表明, 2000 份自交系在 4 年各个鉴定 点的丝黑穗病的自然发病程度均表现轻微，仅 2019 年黑龙江哈尔滨鉴定点的部分材料发病较重, 综合 4 年各个点的自然发病鉴定数据, 发现对丝黑穗病 表现感病和高感的种质占比仅分别为 $15.7 \%$ 和 $2.2 \%$, 大部分种质均表现抗病或高抗。由于丝黑穗病在 4 年的各个鉴定点的自然发病程度均不充分, 抗病种 质鉴定的数据难以真实反映种质的抗性水平, 因此, 抗病鉴定种质的结果仅供参考。

2.2 .9 粗缩病鉴定粗缩病是黄淮海地区和热带 亚热带玉米生产上的重要病害。2016-2019 年期间, 重点调查河南原阳、山东章丘、北京顺义和北京房 山鉴定点的情况表明，各年度间各鉴定点的粗缩病 自然发病程度整体较轻, 仅 2019 年山东章丘发生 较重, 2000 份自交系中, 对粗缩病表现感病和高感 的自交系分别占总鉴定种质的 $26.2 \%$ 和 $9.6 \%$ 。综合 4 年各个鉴定点的自然发病鉴定数据, 对粗缩病表 现高抗和抗病的种质分别为 803 份和 382 份, 由于 粗缩病的发生程度取决于灰飞虫种群数量、带毒率 及其玉米感病敏感期吻合性, 4 年间仅 1 个点的自 然发病程度较重, 因此粗缩病抗病种质的数据仅供 参考。

\subsubsection{0 玉米种质资源对多种病害的综合抗性}

通过对 4 年各个点的自然发病鉴定数据综合 分析, 发现部分材料的综合抗性突出, 兼抗多种重 要病害, JN15、953、沈 977、68122、K21、SC24-1、 $17 \mathrm{MC} 7211 、 17 \mathrm{MC} 7223$ 、郑 591、161191等种质在 4 年多点的自然发病鉴定中, 对上述 9 种病害均表 现出中抗至高抗水平, 中自 $01 、 17 \mathrm{MC} 2633$ 、 CT3566、郑 N6、MC7549 等种质的综合抗性也较 为突出, 在田间对 8 种病害表现抗病, 这些兼抗多 种病害的材料将是用于后续进一步鉴定和研究的 重要候选种质。

\section{3 讨论}

玉米作为我国第一大粮饲兼用作物，在农业生 产中占有极其重要的地位。保障玉米安全生产, 降 低生产成本, 不断提高玉米的产量和品质, 对于促 进玉米产业的健康发展具有重要意义。病害是玉米 生产上的重要限制因子，已成为制约我国玉米高产 稳产的重要因素, 严重威胁玉米的安全生产和产业 的健康发展。2002年东北地区因丝黑穗病大发生减 产 13 万吨; 2008 年山东玉米粗缩病发生面积达 186.7 万公顷, 重病区济宁市因病减产 56.6 万吨, 直接损 失9.1亿元; 2012年全国因大斑病的暴发造成减产 46.6 万吨 ${ }^{[46]}$ 。因此, 控制玉米病害, 对于保障玉米的 安全生产具有重要意义。

国内外大量的生产实践和研究表明, 利用抗性 品种是防治玉米病害的经济有效措施。在 20 世纪 70 年代中后期, 北方春玉米区大斑病严重发生, 导致 玉米减产约 17 亿千克; 20 世纪 80 年代后，因推广应 用抗大斑病品种沈单 7 号、掖单 13 、丹玉 13 等，大斑 病为害基本得到控制; 但由于抗病品种的抗源较为 单一，抗性被新的生理小种克服, 20 世纪 90 年代初、 2003-2004年以及2012-2014年, 大斑病再次大范 围严重发生, 给玉米生产造成重大损失 ${ }^{[7-8,47]}$ 。因此, 培育具有多抗性、持久抗性的品种逐渐成为育种家 的一个重要目标。

鉴于玉米病害对生产为害的严重性以及品种抗 性的重要性, 在国家玉米新品种审定标准中, 必须 针对品种所在生态区的重要病害进行抗病鉴定, 以 明确新培育品种对适生区域内主要病害的抗性水平 以及推广后可能出现的生产风险。对于常发的重要 病害，实行高感品种“一票否决”制。目前，在我国所 有玉米生态区，对高感茎腐病或穗腐病的品种实行 一票否决; 除此之外, 在黄淮海和京津冀夏玉米区, 
对高感小斑病的品种也实行一票否决, 在东华北春 玉米区, 对高感大斑病的品种实行一票否决, 在西 南春玉米类区和热带亚热带玉米区, 对高感纹枯 病、大斑病的品种实行一票否决等。因此, 抗病性 已成为玉米新品种不可或缺的特性。

近年来, 玉米种质和品种的抗病性鉴定与抗病 品种的推广得到了社会的广泛认可。特别是经历了 玉米生产上数次病害大流行的洗礼, 如 2003-2016 年西南地区灰斑病流行、2007-2008 年黄淮海地区

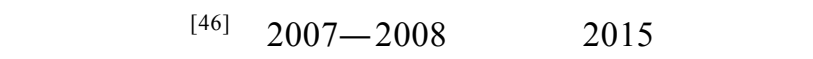
海地区南方锈病大流行 ${ }^{[38,46] 、 2016}$ 年西北地区与 2017 年黄淮海地区的茎腐病流行等 ${ }^{[48-49]}$, 无不给玉 米生产造成严重损失。正因为病害流行所造成的灾 难性后果, 使育种工作者、农民和玉米育种企业对 于品种抗病性认识空前提高, 在 2017 年和 2018 年 的玉米市场, 抗病性已经成为种业公司推广品种和 农户选择品种的最重要指标之一。

种质资源是玉米抗病育种的重要物质基础, 是 保障国家粮食安全和种业健康发展的战略资源, 而 资源的表型精准鉴定是有效利用玉米种质的重要途 径和策略。国内外均十分重视玉米种质资源的抗病 鉴定与评价工作, 针对不同病害开展了一系列抗性 鉴定研究, 䇻选出一些抗病种质, 在此基础上, 开 展抗病种质创制和抗病品种选育与利用, 对于相关 病害的控制起到了十分积极的作用。然而, 以往的 大部分抗性鉴定工作都是在固定的鉴定圃完成的, 很少涉及到多年多点的鉴定与评价, 而玉米病害的 发生程度受环境影响较大, 因此, 上述研究中篮选 出的种质能否在不同环境条件和不同生态区都表现 出稳定的抗性, 尚未可知, 况且, 在当前生产中仍 普遍存在大量对各类病害高度敏感的品种, 一旦条 件适宜, 病害将暴发流行, 对玉米生产造成严重损 失。因此, 对具有广泛遗传背景的玉米种质资源, 开 展多年多点的大规模抗病鉴定, 篮选具有不同遗传 背景且抗性稳定的种质, 对于促进抗病育种, 加速 抗性种质的高效利用, 具有重要意义。

本研究篮选出一批在不同年份和不同环境条件 下都具有稳定抗性的突出种质, 同时, 也获得了一 些对不同病害具有兼抗性的种质。对如此大规模玉 米种质资源进行 4 年多环境的自然发病抗性鉴定, 在国内外尚属首次。尽管与人工接种鉴定相比, 田 间自然发病鉴定确实存在一些不确定性, 如不能保 证同一批次的材料都感染病原菌、病原菌侵染与玉
米敏感生育期能否吻合、田间环境完全不可控、表 型受环境影响更大等; 但由于对同一批材料进行了 连续 4 年的鉴定, 每年都设置 3 8 个具有不同环境 条件的鉴定点, 而且田间自然发病鉴定的条件与大 田生产品种所处的环境完全一致, 在某种意义上讲, 自然发病鉴定的结果更接近于田间真实的抗性水 平。因此, 多年多点的自然发病抗性鉴定结果具有 较大的参考价值, 尤其对于某种病害在多个点的发 病均较为充分的材料, 鉴定结果更能反映出真实的 抗性水平。

我们将鉴定固设置在我国玉米种植面积最大的 东华北和黄淮海地区(由于人力和经费等客观条件的 限制, 西北地区只对部分材料进行了鉴定), 重点调 查了黄淮海和东华北地区玉米生产上的主要病害, 包括小斑病、茎腐病、瘤黑粉病、弯孢叶斑病、南方 锈病、大斑病、灰斑病、粗缩病、丝黑穗病 9 种病害, 其中黄淮海地区重点鉴定了小斑病、茎腐病、瘤黑粉 病、弯狍叶斑病、南方锈病和粗缩病的发病程度, 东 华北地区主要鉴定了茎腐病、大斑病、灰斑病和丝黑 穗病的自然发病状况。穗腐病也是各个生态区玉米生 产上的重要病害, 但由于本研究中的 2000 份玉米种 质，除用于自然发病鉴定外，还进行部分农艺性状的 鉴定如穗柄长、苞叶片数、苞叶长、穗长、穗粗、穗 行数、行粒数、百粒重等, 而穗腐病调查时需要录掉 苞叶, 逐穗查看, 为了不影响上述农艺性状的鉴定, 因此没有进行穗腐病调查。

小玟病在多个年份和多个鉴定点的发病程度均 比较充分, 故小斑病的抗鉴结果能较为真实地反映 该种质的抗性水平; 其次是茎腐病、大斑病和灰斑 病, 在部分鉴定点发病较为充分, 综合抗鉴结果具 有较大的参考价值; 粗缩病、弯孢叶斑病和瘤黑粉 病仅有 1 个点发病较为充分, 而丝黑穗病和南方锈 病在 2016-2019 年的各个点发病程度均比较轻, 因 此, 除了感病数据外, 鉴定为抗病种质的结果仅供 参考。

通过对 2000 份遗传背景丰富的种质进行多年 多点的大规模自然发病鉴定, 结合相关农艺性状, 我们篮选出约 500 份代表性种质, 用于后续的人工 接种抗性精准鉴定, 进一步明确其在不同环境下的 抗性水平，篮选出不同年份和不同环境下对某种病 害或几种病害具有稳定抗性的玉米种质, 为抗病育 种提供物质基础。研究结果将加速抗病品种的选育 与推广应用, 对于减少农药使用量、降低生产成本 
和增加生产效益具有积极的意义。

\section{4 结论}

在黄淮海和东华北地区，首次对 2000 份来源广 泛且遗传背景丰富的玉米种质资源进行了多年多点 以小斑病、茎腐病、瘤黑粉病、弯孢叶斑病、南方 锈病、粗缩病、大斑病、灰斑病和丝黑穗病为重点 的田间自然发病抗性鉴定。鉴定结果受环境因素影 响较大。小玟病在多个年份和多个鉴定点的发病程 度均比较充分, 茎腐病、大斑病和灰斑病, 在不同年 份的部分鉴定点发病较为充分，其综合抗鉴结果具 有较大的参考价值。通过 4 年 10 个不同环境的大规 模自然发病鉴定，篮选出一批在不同环境条件下均 具有稳定抗性的种质, 为抗性种质的利用以及后续 人工接种精准鉴定的种质选择提供了重要参考。

\section{References}

[1] Deutsch C A, Tewksbury J J, Tigchelaar M, Battisti D S, Merrill S C, Huey R B, Naylor R L. Increase in crop losses to insect pests in a warming climate. Science, 2018, 361: 916-919.

[2] 王振营, 王晓鸣. 我国玉米病虫害发生现状、趋势与防控对策. 植物保护, 2019, 45(1): 1-11.

Wang Z Y, Wang X M. Current status and management strategies for corn pests and diseases in China. Plant Prot, 2019, 45(1): 1-11 (in Chinese with English abstract).

[3] Savary S, Willocquet L, Pethybridge S J, Esker P, McRoberts N, Nelson A. The global burden of pathogens and pests on major food crops. Nat Ecol Evol, 2019, 3: 430-439.

[4] 刘万才, 刘振东, 黄冲, 陆明红, 刘杰, 杨清坡. 近 10 年农作 物主要病虫害发生危害情况的统计和分析. 植物保护, 2016, 42(5): 1-9.

Liu W C, Liu Z D, Huang C, Lu M H, Liu J, Yang Q P. Statistics and analysis of crop yield losses caused by main diseases and insect pests in recent 10 years. Plant Prot, 2016, 42(5): 1-9 (in Chinese with English abstract).

[5] 王晓鸣, 石洁, 晋齐鸣, 李晓, 孙世贤. 玉米病虫害田间手册. 北京: 中国农业科学技术出版社, 2010. pp 7-10.

Wang X M, Shi J, Jin Q M, Li X, Sun S X. Field Manual for Corn Diseases and Pests. Beijing: China Agricultural Science and Technology Press, 2010. pp 7-10 (in Chinese).

[6] Hooker A L, Smith B R, Lim S M, Musson M D. Physiologicraces of Helminthosporium maydis and disease resistance. Plant Dis Rep, 1970, 54: 1109-1110.

[7] 王晓鸣, 晋齐鸣, 石洁, 王作英, 李晓. 玉米病害发生现状与 推广品种抗性对未来病害发展的影响. 植物病理学报, 2006, 36: $1-11$.

Wang X M, Jin Q M, Shi J, Wang Z Y, Li X. The status of maize diseases and the possible effect of variety resistance on disease occurrence in the future. Acta Phytopathol Sin, 2006, 36: 1-11 (in Chinese with English abstract).

[8] 刘杰, 姜玉英, 曾娟. 2012 年玉米大斑病重发原因与控制对策. 植物保护, 2013, 39(6): 86-90.
Liu J, Jiang Y Y, Zeng J. Analysis of northern corn leaf blight epidemic in 2012 and control countermeasures. Plant Prot, 2013, 39(6): 86-90 (in Chinese with English abstract).

[9] 苏前富, 张伟, 宋淑云, 晋齐鸣, 李红, 张欣芳, 隋晶. 2007 年 吉林省玉米主要病害调查及其发生趋势预测. 玉米科学, 2008, 16(5): 135-137.

Su Q F, Zhang W, Song S Y, Jin Q M, Li H, Zhang X F, Sui J. Research and forecast of catastrophic tendency of the main corn diseases in Jilin province in 2007. J Maize Sci, 2008, 16(5): 135-137 (in Chinese with English abstract).

[10] 刘庆奎, 秦子惠, 张小利, 江凯, 陈茂功, 武小菲, 何月秋, 王 桂清, 晋齐鸣, 王晓鸣. 中国玉米灰斑病病原菌的鉴定及其基 本特征研究. 中国农业科学, 2013, 46: 4044-4057.

Liu Q K, Qin Z H, Zhang X L, Jiang K, Chen M G, Wu X F, He Y Q, Wang G Q, Jin Q M, Wang X M. Identification of Cercospora species associated with maize gray leaf spot in China. Sci Agric Sin, 2013, 46: 4044-4057 (in Chinese with English abstract).

[11] 张小飞, 李晓, 崔丽娜, 邹成佳, 杨晓蓉. 西南地区玉米灰斑 病病原种类分子鉴定. 西南农业学报, 2014, 27: 1079-1081.

Zhang X F, Li X, Cui L N, Zou C J, Yang X R. Molecular identification of race from maize gray leaf spot in Southwest China. Southwest China J Agric Sci, 2014, 27: 1079-1081 (in Chinese with English abstract).

[12] 赵立萍, 王晓鸣, 段灿星, 龙书生, 李晓, 李洪连, 何月秋, 晋 齐鸣, 武小菲, 宋凤景. 中国玉米灰斑病发生现状与未来扩散 趋势分析. 中国农业科学, 2015, 48: 3612-3626.

Zhao L P, Wang X M, Duan C X, Long S S, Li X, Li H L, He Y Q, Jin Q M, Wu X F, Song F J. Occurrence status and future spreading areas of maize gray leaf spot in China. Sci Agric Sin, 2015, 48: 3612-3626 (in Chinese with English abstract).

[13] 石洁, 刘玉瑛, 刘爱国, 王连生. 河北省玉米弯孢霉菌叶斑病 发生调查. 河北农业大学学报, 1998, 21(2): 94.

Shi J, Liu Y Y, Liu A G, Wang L S. Investigation on the occurrence of maize curvularia leaf spot in Hebei province. J Agric Univ Hebei, 1998, 21(2): 94 (in Chinese with English abstract).

[14] 王寿伦. 山东、河南和江苏部分地区玉米锈病 1998 年流行. 植 保技术与推广, 1999, 19(3): 40-41.

Wang S L. Southern corn rust was epidemic in Shandong, Henan and Jiangsu provinces in 1998. Plant Prot Technol Exten, 1999, 19(3): 40-41 (in Chinese).

[15] 陈文娟, 李万昌, 杨知还, 孙素丽, 王晓鸣, 朱振东, 段灿星. 玉米抗南方锈病种质资源初步鉴定及遗传多样性分析. 植物 遗传资源学报, 2018, 19: 194-201.

Chen W J, Li W C, Yang Z H, Sun S L, Wang X M, Zhu Z D, Duan C X. Preliminary identification and genetic diversity analysis of maize germplasm resources for resistance to southern corn rust. J Plant Genet Resour, 2018, 19: 194-201 (in Chinese with English abstract).

[16] Khokhar M K, Hooda K S, Sharma S S, Singh V. Post flowering stalk rot complex of maize-present status and future prospects. Maydica, 2014, 59: 226-242.

[17] 段灿星, 王晓鸣, 武小菲, 杨知还, 宋凤景, 赵立萍, 孙素丽, 朱振东. 玉米种质和新品种对腐霉茎腐病和镰狍穗腐病的抗 性分析. 植物遗传资源学报, 2015, 16: 947-954.

Duan C X, Wang X M, Wu X F, Yang Z H, Song F J, Zhao L P, Sun S L, Zhu Z D. Analysis of maize accessions resistance to 
Pythium Stalk rot and Fusarium ear rot. J Plant Genet Resour, 2015, 16: 947-954 (in Chinese with English abstract).

[18] 郭满库, 王晓鸣, 何苏琴, 刘永刚, 金社林, 曹世勤, 魏宏玉. 2009 年甘肃省玉米穗腐病、茎基腐病的发生危害. 植物保护, 2011, 37(4): 134-137.

Guo M K, Wang X M, He S Q, Liu Y G, Jin S L, Cao S Q, Wei H Y. Occurrence of maize kernel rot and corn stalk rot in Gansu in 2009. Plant Prot, 2011, 37(4): 134-137 (in Chinese with English abstract).

[19] 段灿星, 王晓鸣, 宋凤景, 孙素丽, 周丹妮, 朱振东. 玉米抗 穗腐病研究进展. 中国农业科学, 2015, 48: 2152-2164.

Duan C X, Wang X M, Song F J, Sun S L, Zhou D N, Zhu Z D. Advances in research on maize resistance to ear rot. Sci Agric Sin, 2015, 48: 2152-2164 (in Chinese with English abstract).

[20] Yoshizawa T, Yamashita A, Luo Y. Fumonisin occurrence in corn form high-risk and low-risk areas for human esophageal cancer in China. Appl Environ Microbiol, 1994, 60: 1626-1629.

[21] Bush B J, Carson M L, Cubeta M A, Hagler W M, Payne G A. Infection and fumonisin production by Fusarium verticillioides in developing maize kernels. Phytopathology, 2004, 94: 88-93.

[22] Duan C X, Qin Z H, Yang Z H, Li W X, Sun S L, Zhu Z D, Wang $\mathrm{X}$ M. Identification of pathogenic Fusarium spp. causing maize ear rot and potential mycotoxin production in China. Toxins, 2016, 8: 186.

[23] Zhou D N, Wang X M, Chen G K, Sun S L, Yang Y, Zhu Z D, Duan C X. The major Fusarium species causing maize ear and kernel rot and their toxigenicity in Chongqing, China. Toxins, 2018, 10: 90.

[24] 杜青, 唐照磊, 李石初, 上官玲玲, 李华娇, 段灿星. 广西玉 米穗腐病致病镰狍种群构成与毒素化学型分析. 中国农业科 学, 2019, 52: 1895-1907.

Du Q, Tang Z L, Li S C, Shang-Guan L L, Li H J, Duan C X. Composition of Fusarium species causing maize ear rot and analysis of toxigenic chemotype in Guangxi. Sci Agric Sin, 2019, 52: 1895-1907 (in Chinese with English abstract).

[25] Clements M J, Kleinschmidt C E, Maragos C M, Pataky J K, White D G. Evaluation of inoculation techniques for Fusarium ear rot and fumonisin contamination of corn. Plant Dis, 2003, 87: $147-153$

[26] 杨洋, 陈国康, 郭成, 张炜, 孙素丽, 王晓鸣, 朱振东, 段灿星. 玉米种质资源抗腐霉茎腐病鉴定. 作物学报, 2018，44: 1256-1260.

Yang Y, Chen G K, Guo C, Zhang W, Sun S L, Wang X M, Zhu Z D, Duan C X. Identification of maize germplasm for resistance to Pythium stalk rot. Acta Agron Sin, 2018, 44: 1256-1260 (in Chinese with English abstract).

[27] 渠清, 李丽娜, 刘俊, 王绍新, 曹志艳, 董金鼻. 我国部分常 用玉米种质资源对镰狍菌病害的抗性评价. 中国农业科学, 2019, 52: 2962-2971.

Qu Q, Li L N, Liu J, Wang S X, Cao Z Y, Dong J G. Resistance evaluation of some commonly used maize germplasm resources to Fusarium diseases in China. Sci Agric Sin, 2019, 52: 2962-2971 (in Chinese with English abstract).

[28] Stagnati L, Lanubile A, Samayoa L F, Bragalanti M, Giorni P, Busconi M, Holland J B, Marocco A. A genome wide association study reveals markers and genes associated with resistance to
Fusarium verticillioides infection of seedlings in a maize diversity panel. G3: Genes Genom Genet, 2019, 9: 571-579.

[29] Afolabi C G, Ojiambo P S, Ekpo E J A, Menkir A, Bandyopadhyay R. Novel sources of resistance to Fusarium stalk rot of maize in tropical Africa. Plant Dis, 2008, 92: 772-780.

[30] Santiago R, Reid L M, Zhu X, Butrón A, Malvar R A. Gibberella stalk rot (Fusarium graminearum) resistance of maize inbreds and their $F_{1}$ hybrids and their potential for use in resistance breeding programs. Plant Breed, 2010, 129: 454-456.

[31] 段灿星, 朱振东, 武小菲, 杨知还, 王晓鸣. 玉米种质资源对 六种重要病虫害的抗性鉴定与评价. 植物遗传资源学报, 2012, 13: $169-174$.

Duan C X, Zhu Z D, Wu X F, Yang Z H, Wang X M. Screening and evaluation of maize germplasm for resistance to five diseases and Asian corn borer. J Plant Genet Resour, 2012, 13: 169-174 (in Chinese with English abstract).

[32] Kebebe A Z, Reid L M, Zhu X, Wu J, Woldemariam T, Voloaca C, Xiang K. Relationship between kernel drydown rate and resistance to gibberella ear rot in maize. Euphytica, 2015, 201: 79-88.

[33] 王春明, 郭成, 周天旺, 段灿星. 629 份国内外玉米种质及杂交 种对丝黑穗病的抗性评价. 草地学报, 2019, 27: 1075-1082. Wang C M, Guo C, Zhou T W, Duan C X. Evaluation on resistance to head smut of 629 maize germplasm resources and hybrids from domestic and hybrids from domestic and overseas. Acta Agretia Sin, 2019, 27: 1075-1082 (in Chinese with English abstract).

[34] Duan C X, Song F J, Sun S L, Guo C, Zhu Z D, Wang X M. Characterization and molecular mapping of two novel genes resistance to Pythium stalk rot in maize. Phytopathology, 2019, 109: 804-809.

[35] 徐婧, 姜钰, 秦培文, 刘可杰, 胡兰, 孙会杰, 徐秀德. 外引玉 米种质对两种穗腐病原镰狍菌抗性鉴定. 植物遗传资源学报, 2019, 20: 20-25.

Xu J, Jiang Y, Qin P W, Liu K J, Hu L, Sun H J, Xu X D. Test for ear rot resistance against Fusarium verticillioides and Fusarium graminearum in imported maize germplasm. J Plant Genet Resour, 2019, 20: 20-25 (in Chinese with English abstract).

[36] 王晓鸣, 戴法超, 朱振东, 何康来, 王锡峰. 玉米抗病虫性鉴 定技术规范, 第 2 部分 玉米抗小斑病鉴定技术规范(NY/T 1248.2-2006). 北京: 中国农业出版社, 2007.

Wang X M, Dai F C, Zhu Z D, He K L, Wang X F. Rules for Evaluation of Maize for Resistance to Pests. Part 2: Rule for evaluation of maize for resistance to southern corn leaf blight (NY/T 1248.2-2006). Beijing: China Agriculture Press, 2007 (in Chinese).

[37] 王晓鸣, 孙世贤, 石洁, 李晓, 晋齐鸣. 玉米抗病虫性鉴定技 术规范 第 10 部分: 弯狍叶斑病(NY/T 1248.10-2016). 北京: 中国农业出版社, 2017.

Wang X M, Sun S X, Shi J, Li X, Jin Q M. Technical Specification on Evaluation of Maize Resistance to Pests. Part 10: Curvularia leaf spot (NY/T 1248.10-2016). Beijing: China Agriculture Press, 2017 (in Chinese).

[38] 陈文娟, 路璐, 李万昌, 张小杰, 孙素丽, 朱振东, 王晓鸣, 段 灿星. 玉米抗南方锈病基因的 QTL 定位. 植物遗传资源学报, 2019, 20: 521-529.

Chen W J, Lu L, Li W C, Zhang X J, Sun S L, Zhu Z D, Wang X 
M, Duan C X. QTL mapping for resistance to southern corn rust in maize. J Plant Genet Resour, 2019, 20: 521-529 (in Chinese with English abstract).

[39] 王晓鸣, 戴法超, 朱振东, 何康来, 王锡峰. 玉米抗病虫性鉴 定技术规范, 第 1 部分: 玉米抗大斑病鉴定技术规范(NY/T 1248.1-2006). 北京: 中国农业出版社, 2007.

Wang X M, Dai F C, Zhu Z D, He K L, Wang X F. Rules for Evaluation of Maize for Resistance to Pests. Part 1: Rule for evaluation of maize for resistance to northern corn leaf blight (NY/T 1248.1-2006). Beijing: China Agriculture Press, 2007 (in Chinese).

[40] 王晓鸣, 孙世贤, 石洁, 李晓, 晋齐鸣. 玉米抗病虫性鉴定技 术规范 第 11 部分: 灰斑病(NY/T 1248.11-2016). 北京: 中国 农业出版社, 2017.

Wang X M, Sun S X, Shi J, Li X, Jin Q M. Technical Specification on Evaluation of Maize Resistance to Pests. Part 11: Gray leaf spot (NY/T 1248.11-2016). Beijing: China Agriculture Press, 2017 (in Chinese).

[41] 王晓鸣, 孙世贤, 石洁, 李晓, 晋齐鸣. 玉米抗病虫性鉴定技 术规范 第 6 部分: 腐霉茎腐病(NY/T 1248.6-2016). 北京: 中 国农业出版社, 2017.

Wang X M, Sun S X, Shi J, Li X, Jin Q M. Technical Specification on Evaluation of Maize Resistance to Pests. Part 6: Pythium stalk rot (NY/T 1248.6-2016). Beijing: China Agriculture Press, 2017 (in Chinese).

[42] 王晓鸣, 孙世贤, 石洁, 李晓, 晋齐鸣. 玉米抗病虫性鉴定技 术规范 第 7 部分: 镰孢茎腐病(NY/T 1248.7-2016). 北京: 中 国农业出版社, 2017.

Wang X M, Sun S X, Shi J, Li X, Jin Q M. Technical Specification on Evaluation of Maize Resistance to Pests. Part 7: Fusarium and Gibberella stalk rot (NY/T 1248.7-2016). Beijing: China Agriculture Press, 2017 (in Chinese).

[43] 王晓鸣, 孙世贤, 石洁, 李晓, 晋齐鸣. 玉米抗病虫性鉴定技 术规范 第 12 部分: 瘤黑粉病(NY/T 1248.12-2016). 北京: 中 国农业出版社, 2017.

Wang X M, Sun S X, Shi J, Li X, Jin Q M. Technical Specification on Evaluation of Maize Resistance to Pests. Part 12: Common smut (NY/T 1248.12-2016). Beijing: China Agriculture Press, 2017 (in Chinese).

[44] 王晓鸣, 戴法超, 朱振东, 何康来, 王锡峰. 玉米抗病虫性鉴
定技术规范 第 3 部分: 玉米抗丝黑穗病鉴定技术规范(NY/T 1248.3-2006). 北京: 中国农业出版社, 2007.

Wang X M, Dai F C, Zhu Z D, He K L, Wang X F. Rules for Evaluation of Maize for Resistance to Pests. Part 3: Rule for evaluation of maize for resistance to head smut (NY/T 1248.3-2006). Beijing: China Agriculture Press, 2007 (in Chinese).

[45] 王晓鸣, 孙世贤, 石洁, 李晓, 晋齐鸣. 玉米抗病虫性鉴定技 术规范 第 13 部分: 粗缩病(NY/T 1248.13-2016). 北京: 中国 农业出版社, 2017.

Wang X M, Sun S X, Shi J, Li X, Jin Q M. Technical Specification on Evaluation of Maize Resistance to Pests. Part 13: Maize rough dwarf disease (NY/T 1248.13-2016). Beijing: China Agriculture Press, 2017 (in Chinese).

[46] 中国农业科学院植物保护研究所, 中国植物保护学会. 中国 农作物病虫害(第 3 版). 北京: 中国农业出版社, 2015. pp 570-664.

Institute of Plant Protection, Chinese Academy of Agricultural Sciences. China Society of Plant Protection. Crop Diseases and Insect Pests in China, 3rd edn. Beijing: China Agriculture Press, 2015. pp 570-664 (in Chinese).

[47] 赵书文, 杨秀林, 郭东. 玉米大斑病的流行原因与综合治理措 施. 中国植保导刊, 2005, 25(3): 10-12.

Zhao S W, Yang X L, Guo D. Epidemic causes of Exserochilum turcicum and its integrated management measures. China Plant Prot, 2005, 25(3): 10-12 (in Chinese with English abstract).

[48] 郭成, 王宝宝, 杨洋, 王春明, 周天旺, 李敏权, 段灿星. 玉米 茎腐病研究进展. 植物遗传资源学报, 2019, 20: 1118-1128.

Guo C, Wang B B, Yang Y, Wang C M, Zhou T W, Li M Q, Duan C X. Advances in studies of maize stalk rot. J Plant Genet Resour, 2019, 20: 1118-1128 (in Chinese with English abstract).

[49] 刘树森, 马红霞, 郭宁, 石洁, 张海剑, 孙华, 金戈. 黄淮海夏 玉米主产区茎腐病主要病原菌及优势种分析. 中国农业科学, 2019, 52: 262-272.

Liu S S, Ma H X, Guo N, Shi J, Zhang H J, Sun H, Jin G. Analysis of main pathogens and dominant species of maize stalk rot in the main summer maize producing areas of Huang-Huai-Hai. Sci Agric Sin, 2019, 52: 262-272 (in Chinese with English abstract). 